\title{
Geologia
}

\section{O Manto Litosférico Continental na Região do Cerro de Los Chenques, Argentina: Evidências de Heterogeneidade e Metassomatismo}

\author{
Norberto Rieck Jr. ${ }^{1}$ (norberto.rieck@ufrgs.br), Rommulo Vieira Conceição ${ }^{2,3}$, Edinei Koester ${ }^{3}$, Celine Dantas ${ }^{4}$ \\ 'Bolsista do CNPq - Brasil - Programa de Pós-Graduação em Geociências - Instituto de Geociências - UFRGS \\ Av. Bento Gonçalves 9500, CEP 91501-970, Porto Alegre, RS, BRA \\ ${ }^{2}$ Departamento de Geologia - Instituto de Geociências - UFRGS, Porto Alegre, RS, BRA \\ ${ }^{3}$ Laboratório de Geologia Isotópica - Instituto de Geociências - UFRGS, Porto Alegre, RS, BRA \\ ${ }^{4} U M R$ - Observatoire Midi Pyrénées, Toulouse, FRA \\ Recebido em 02 de março de 2006; aceito em 09 de agosto de 2006
}

Palavras-chave: manto litosférico, metassomatismo, Patagônia, Argentina.

\section{RESUMO}

A suíte de xenólitos ultramáficos do Cerro de los Chenques, norte da Patagônia (4452’19”S/ 7003’57’W), extremo sul da América do Sul, consiste de amostras do manto litosférico continental. Dados petrográficos, mineralógicos e geoquímicos de rocha total para elementos maiores e menores mostram que os xenólitos, aqui estudados, consistem de espinélio lherzolitos, harzburgitos e websteritos, com paragênese mineralógica primária formada por olivina, enstatita, diopsídio e espinélio. Dados de elementos maiores em minerais mostram que esta paragênese está em equilíbrio, o que pode ser observado pelo $\mathrm{Mg} \#\left[\mathrm{Mg} /\left(\mathrm{Mg}+\mathrm{Fe}_{\text {total }}\right)\right]$ dos minerais, menor na olivina e maior no diopsídio. Porém, ocorrem instabilidades localizadas com formação de vidro e da paragênese secundária formada por olivina, diopsídio e espinélio. Os xenólitos apresentam ainda dados geoquímicos de rocha total com empobrecimento nos álcalis e nos traços em relação ao manto primitivo, evidenciando o processo de fusão parcial em dois eventos distintos, um relacionado aos peridotitos e outro aos websteritos. Contudo, algumas amostras apresentam também evidências de metassomatismo, denotado pelo re-enriquecimento nos ETR leves em relação aos pesados. Os elementos traço destas amostras mostram um leve enriquecimento dos elementos mais incompatíveis em relação aos mais compatíveis, o que auxilia o entendimento do metassomatismo.

Keywords: lithospheric mantle, metasomatism, Patagonia, Argentina.

\section{ABSTRACT}

The Cerro de los Chenques ultramafic xenolith suite from northern Patagonia (4452'19’S/7003’57’W), southern South America, consists of continental lithospheric mantle samples. Petrographical, mineralogical and geochemical whole rock data for minor and major elements demonstrate that the Cerro de los Chenques xenoliths include spinel-bearing lherzolite, harzburgite and websterite, with primary mineralogical parageneses formed by olivine, enstatite, diopside and spinel. Mineral chemistry data suggest that this paragenesis is in equilibrium, as can be observed by the $\mathrm{Mg} \#\left[\mathrm{Mg} /\left(\mathrm{Mg}+\mathrm{Fe}_{\text {total }}\right)\right]$ of the minerals, lower in olivine and higher in diopside. However, local instabilities occured with the formation of glass and secondary parageneses, constituted by olivine, diopside and spinel. Whole rock geochemical data show depletion on the alkalis and on trace elements in relation to primitive mantle, due to partial melting during two distinct events, one of which involved the peridotites, the other, the websterites. Some samples also present signs of metasomatism involving re-charging of light REE relative to heavy REE. The trace elements of these samples demonstrate slight enrichment of the most incompatible elements in relation to the most compatible, helping the understanding of the metasomatic process. 


\section{INTRODUÇÃO}

Xenólitos ultramáficos inclusos em basaltos alcalinos continentais de idades Oligoceno-Pleistoceno são amostras diretas do manto litosférico continental na Patagônia. O estudo destes xenólitos tem demonstrado que o manto litosférico corresponde ao resíduo de variados graus de fusão do manto superior. Este material também é heterogêneo devido a processos posteriores de re-enriquecimento através de eventos metassomáticos produzidos pela interação de fluidos astenosféricos ou de fluidos derivados das placas subductantes, associados a uma tectônica compressiva. Neste trabalho pretende-se mostrar que os xenólitos do Cerro de los Chenques, que correspondem a lherzolitos, websteritos e harzburgitos, passaram por processos de fusão parcial e posterior metassomatismo.

Estão relatados, aqui, dados petrográficos, de química mineral e de rocha total para treze amostras de xenólitos. $\mathrm{O}$ objetivo é demonstrar que os processos dominantes que controlam a composição dos xenólitos ultramáficos do Cerro de los Chenques são a interação química de líquidos silicatados do próprio manto astenosférico e da placa subductada, os quais produzem características químicas normalmente encontradas em xenólitos do manto metassomatizados.

\section{CONTEXTO GEOLÓGICO}

O Cerro de los Chenques está situado na província de Chubut à distância de $203 \mathrm{~km}$ ao oeste da cidade de Comodoro Rivadavia. Localiza-se no norte da Patagônia (4452'19”S/ 7003’57”W), a $400 \mathrm{~km}$ a nordeste do atual ponto triplo entre as placas oceânicas de Nazca e Antártica e a placa continental da América do Sul que forma o gap vulcânico entre os arcos vulcânicos Sul (ZVS) e Austral (ZVA), atribuído à subducção da Dorsal do Chile (Candie e Leslie, 1986) (Figura 1). Na região Andina, diversos eventos vulcânicos que foram atuantes na região de back-arc patagônica e resultaram em extensos derrames na forma de platôs denominados por Ramos et al. (1982) de Patagonian Plateau Lavas. A origem dos platôs (Gorring e Kay, 2001), na porção norte da Patagônia, está relacionada à formação de hotspots efêmeros, como afirmam Kay et al. (1992) para o platô de Sommuncurá, enquanto que na porção sul da Patagônia esses platôs vulcânicos foram gerados a partir da fusão e ascensão de material do manto subastenosférico através de janelas formadas pela interação da placa subductada e da crosta continental (Ramos e Kay, 1992; Gorring et al., 1997). As rochas vulcânicas do Cerro de los Chenques cortam sedimentos quaternários de origem glacial (Ploszkiewicz, 1987) e, portanto podem ser interpretados como um vulcanismo post-plateau. Estes eventos vul- cânicos, tanto no norte como no sul, são responsáveis pelo transporte à superfície de fragmentos de manto, os xenólitos ultramáficos. O Cerro de los Chenques apresenta rochas relacionadas a evento piroclástico onde é possível observar uma grande quantidade de bombas piroclásticas. Os xenólitos ultramáficos estão inclusos nestas rochas vulcânicas, têm formato subarredondado a elipsoidal, com dimensões variando de 4 a $15 \mathrm{~cm}$. Os contatos com a rocha hospedeira são abruptos.

\section{MÉTODOS ANALÍTICOS}

A petrologia foi realizada com auxílio de microscópio óptico. A composição modal dos xenólitos foi calculada contando dois mil pontos, utilizando contador de pontos manual. Os dados de geoquímica de elementos maiores para minerais da paragênese primária foram obtidos no laboratório LMTG - Université Paul Sabatier, Toulouse, através de uma microssonda eletrônica CAMECA SX 50 com 3 espectrômetros WDS PET-TAP-LiF. Utilizou-se uma rotina padrão empregando $15 \mathrm{Kv}$ de tensão de aceleração, 20 nA de corrente, $2 \times 2 \mu \mathrm{m}$ de feixe, tempos de contagem de 20 s para Ti, Fe, Ca, Mn, e 30 s para Mg, Al, Ni, Ba, Cr, Na e Si. As análises de microssonda eletrônica utilizaram padrões de minerais internacionais e apresentam um erro (desvio padrão) inferior a $10 \%$, exceção feita às análises de $\mathrm{CaO}$ nas olivinas, que devido à baixa concentração, podem apresentar erros superiores. Imagens da paragênese secundária foram obtidas por microscopia eletrônica de varredura, através do sistema de Espectroscopia por Dispersão de Energia (Energy Dispersive System-EDS), no Centro de Microscopia Eletrônica-UFRGS. As análises de elementos maiores de rocha total foram realizadas no Laboratório de Fluorescência de Raios X do CPGq-IG-UFRGS, através de um espectrômetro de Fluorescência de Raios X Rigaku RIX 2000 com calibração de acordo com procedimentos convencionais, definidas por padrões geológicos internacionais (e.g. JA-1, JB-1, JG-2). As análises dos elementos traço em rocha total foram realizadas no laboratório LMTG - Université Paul Sabatier, Toulouse, através de um espectrômetro de massa acoplado a um plasma induzido (ICP-MS). Utilizou-se cerca de $200 \mathrm{mg}$ de rocha total pulverizada e dissolvida utilizando procedimentos com misturas

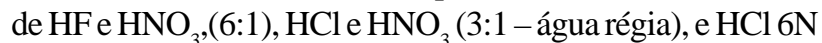
até a dissolução completa do material em frascos de teflon (Savillex ${ }^{\circledR}$ ) aquecidos em chapa quente a temperaturas superiores a $100^{\circ} \mathrm{C}$. Após a dissolução, o resíduo foi diluído em $7 \mathrm{ml}$ de uma solução de $\mathrm{HNO}_{3} 2 \%$, denominada solução da amostra. Padrões de In e Re foram adicionados à solução da amostra para calibração e determinação dos elementos. Estas soluções foram analisadas em um ICP-MS Alan 6000 Perkin Elmer sob as seguintes condições: fluxo de gás de argônio no nebulizador (0,86 - 0,88 L/min), fluxo de argônio auxiliar 


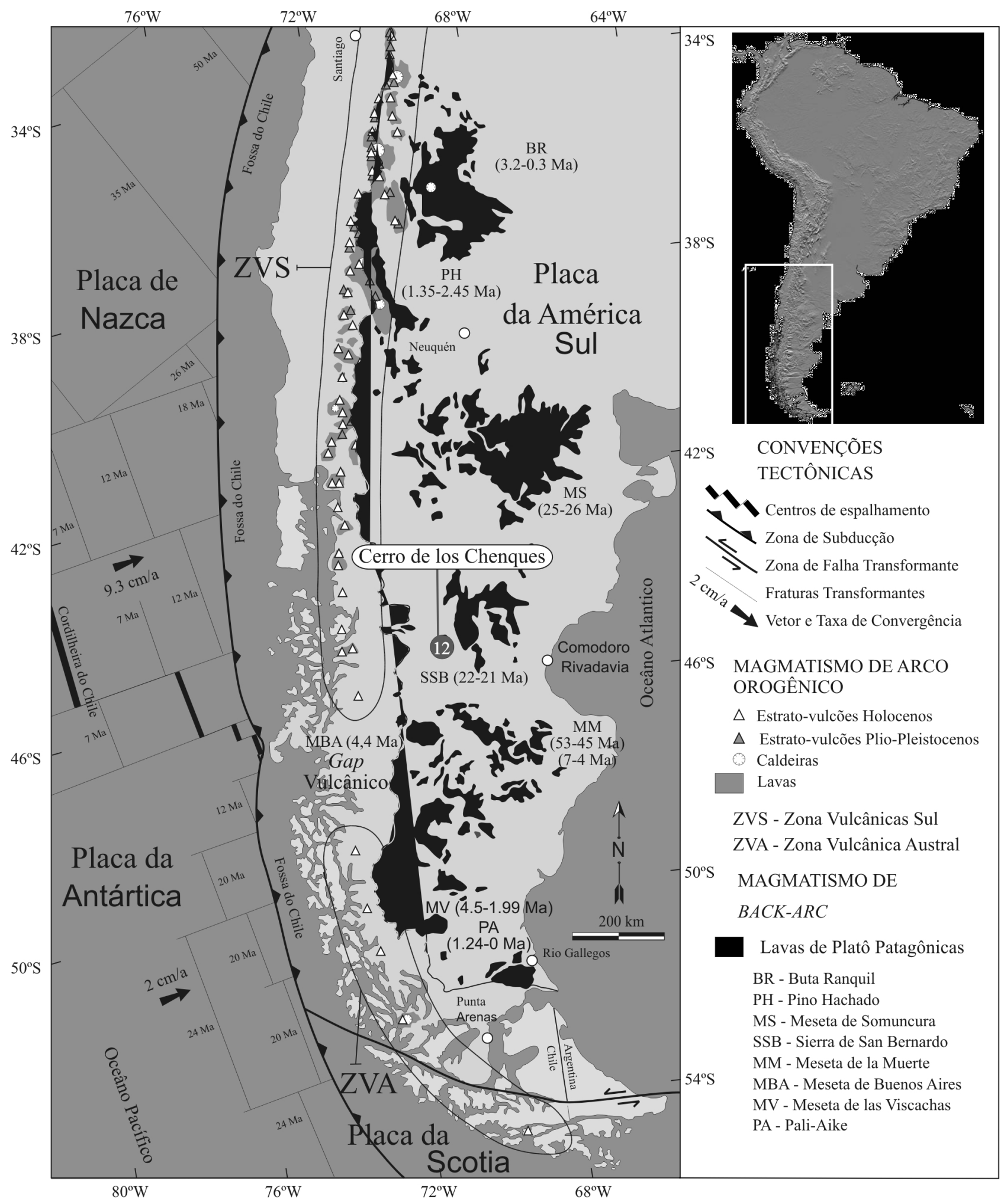

Figura 1. Mapa de localização do Cerro de los Chenques e a distribuição geológica das lavas de platô patagônicas. A configuração das placas de Nazca e Antártica e suas zonas de subducção também estão visualizadas, assim como os arcos vulcânicos e o gap vulcânico. 
(1 L/min), fluxo de gás no plasma $(15 \mathrm{~L} / \mathrm{min})$, modo de varredura (peak hopping). Cada concentração de elemento foi determinada pela média de 10 análises (10 varreduras). O desvio padrão destas análises é inferior a $2 \%$ para cada elemento. A introdução da amostra no ICP-MS é realizada por uma câmara spray ciclônica, um nebulizador Meinhard e uma unidade de dissolução Knauer.

\section{PETROGRAFIA E QUÍMICA MINERAL}

Os xenólitos ultramáficos do Cerro de los Chenques têm paragênese formada por olivina (ol-1), enstatita (opx-1), diopsídio (cpx-1) e espinélio (sp-1) e foram divididos, a partir da petrografia em três grupos de acordo com a composição mineralógica: grupo dos lherzolitos, dos websteritos e dos harzburgitos. Ocorrem localizadamente instabilidades causadas pelos processos de metassomatismo, evidenciadas pela paragênese secundária constituída por diopsídio (cpx-2), olivina (ol-2) e espinélio (sp-2) (Figuras 2a e 2b) e formação de melt pockets (bolsões de vidros silicáticos).

O grupo dos lherzolitos compreende cinco amostras classificadas como espinélio lherzolitos; o dos websteritos também compreende seis amostras de espinélio olivina websteritos e o dos harzburgitos corresponde a apenas uma amostra. Os grupos apresentam, como texturas principais, (Figuras 2c e 2d) a protogranular e a textura transicional porfiroclástica a equigranular, segundo a classificação proposta por Mercier e Nicolas (1975).

Os cristais de ol-1 são porfiroclastos subédricos com dimensões de 1 a 3 mm, cor cinza claro, apresentam ocorrências de estruturas de deformação do tipo kink band, e contatos de $120^{\circ}$ com fenocristais de ortopiroxênios primários opx-1. Os opx-1 são subédricos a euédricos, com dimensões que variam de 1 a $2 \mathrm{~mm}$, têm cor bege, apresentam ocorrências de reações do tipo lamelas de exolução, com formação de cpx nas suas clivagens, em função da diminuição das condições de pressão, e são classificados como cromo-alumínio enstatitas. Os cpx-1 são subédricos, com dimensões em torno de 1,2 mm (sendo os cristais com dimensões de até $2 \mathrm{~mm}$ ), têm cor verde, registram ocorrência de reações denominadas de franjas de recristalização $(>0,1$ mm de espessura) nas bordas dos grãos e são classificados como alumínio-cromo diopsídio. Os sp-1 são anédricos a subédricos, ocorrem intersticialmente com dimensões de 0,3 a 0,8 mm, têm cor marrom escura, apresentam ocorrências de cristais com forma holly-leaf (Mercier e Nicolas, 1975), e são classificados como cromo espinélio.

A paragênese secundária corresponde a minerais de dimensões pequenas (dimensões menores que 0,3 mm), apresentam-se euédricos e estão envoltos ao vidro silicático amorfo.

As análises mineraloquímicas estão expressas na
Tabela 1 e se referem somente a paragênese primária. Estas análises indicam que ela está em equilíbrio, o que é denotado pelo Mg\# (ol-1<opx-1<cpx-1). Nas análises de óxidos versus Mg\# destes minerais, como se pode ver na Figura 3, verifica-se um trend composicional com Mg\# mais baixo nos webteritos do que nos lherzolitos e harzburgitos para as ol-1, opx-1 e cpx-1. Já para o sp-1 o Mg\# é maior nos websteritos. Além disso, percebe-se que as amostras estudadas têm Mg\# mais elevado para ol-1, opx-1 e cpx-1 e menores no sp-1, quando comparadas com xenólitos de outros locais. Na Figura 3, os dados de minerais do Cerro de los Chenques estão plotados juntamente com dados de xenólitos do Cerro Del Mojon, Estancia Alvarez (Mallmann, 2004; Conceição et al., 2005) e Cerro Redondo (Schilling et al., 2005), já que os dois primeiros situam-se ao norte do cerro estudado e o último ao sul, comparando, assim, nossos dados com locais representativos da Patagônia.

Nas ol-1, o NiO se apresenta mais enriquecido nos lherzolitos do que nos websteritos e harzburgitos. Por sua vez, o MnO mostra um trend negativo para os lherzolitos, padrão distinto dos websteritos, que tem um padrão horizontalizado, enquanto que o harzburgito é o mais empobrecido em $\mathrm{MnO}$. Nos opx-1, o $\mathrm{Al}_{2} \mathrm{O}_{3}$ e o $\mathrm{CaO}$ dos websteritos e lherzolitos têm trend composicional semelhante com correlação negativa, mais enriquecido nos websteritos enquanto que o harburgito é o mais empobrecido em CaO. Os cpx-1 apresentam uma correlação positiva do $\mathrm{CaO}$ e Cr\# versus o Mg\# tendo as menores concentrações nos websteritos e as maiores no harzburgito. Na Figura 3, pode-se ver um gráfico $\mathrm{Al}_{2} \mathrm{O}_{3}$ versus $\mathrm{Na}_{2} \mathrm{O}$ para os cpx-1, onde se nota uma correlação positiva, com o harzburgito, tendo as concentrações mais baixas e os websteritos, as mais elevadas. Neste gráfico, percebe-se também que os lherzolitos são mais similares às concentrações de amostras dos lherzolitos do Cerro Redondo e que há um gap composicional que deixa o harzburgito do Cerro de los Chenques muito separado das demais amostras. Este gap também é observado nos demais gráficos do cpx-1 e são provavelmente relacionados à baixa concentração de cpx no harzburgito. No sp-1 o Cr\#, quando comparado com o Mg\#, observa-se um trend composicional negativo, onde a amostra mais enriquecida é o harzburgito que possui concentrações menores às dos harzburgitos do Cerro Del Mojon e Estancia Alvarez. Já as amostras mais empobrecidas são de websteritos, com os lherzolitos apresentando concentrações menores do que o Cerro Redondo.

Quando comparados a xenólitos de outras localidades, é possível perceber, de modo geral, que as amostra estudadas têm os menores valores de Mg\#. Os lherzolitos e websteritos possuem concentrações de $\mathrm{Al}_{2} \mathrm{O}_{3}$ maiores com o harzburgito tendo concentração mais próxima às outras localidades. Apresentam também, os menores valores de Cr\# tanto no cpx-1 como no sp-1 que as demais localidades. 


\section{Pressão e temperatura}

As estimativas de pressão e temperatura de equilíbrio, para a paragênese mineralógica primária dos xenólitos ultramáficos de Cerro de los Chenques, foram calculadas a partir dos métodos de Brey e Köhler (1990) e Köhler e Brey (1990), respectivamente. As estimativas das temperaturas se baseiam nas trocas de moléculas de Ca entre clinopiroxênio e ortopiroxênio, enquanto que a difusão de Ca entre clinopiroxênio e olivina permite estimar as condições de pressão a que os xenólitos foram submetidos. Estas pressões foram aproximadas devido à baixa precisão das análises de Ca em olivina obtidas por microssonda eletrônica.

Das amostras de lherzolitos do Cerro de los Chenques, as únicas que tiveram resultados coerentes foram as amostras PM12-13 (913ㅇ $\mathrm{C}$ e kbar) e PM12-15 (928 ${ }^{\circ} \mathrm{C}$ e $10 \mathrm{kbar}$ ). Nos websteritos, os cálculos de pressão e temperatura foram realizados nas amostras PM12-02 (931 ${ }^{\circ} \mathrm{C}$ e $\left.13 \mathrm{kbar}\right), \mathrm{PM} 12-05$ (970 $\left.{ }^{\circ} \mathrm{Ce} 10 \mathrm{kbar}\right), \mathrm{PM} 12-17\left(1017^{\circ} \mathrm{Ce} 9 \mathrm{kbar}\right) \mathrm{ePM} 12-19\left(1006^{\circ} \mathrm{C}\right.$ e 12 kbar). O harzburgito apresentou dados de pressão e temperaturas incoerentes, com temperatura muito baixa.
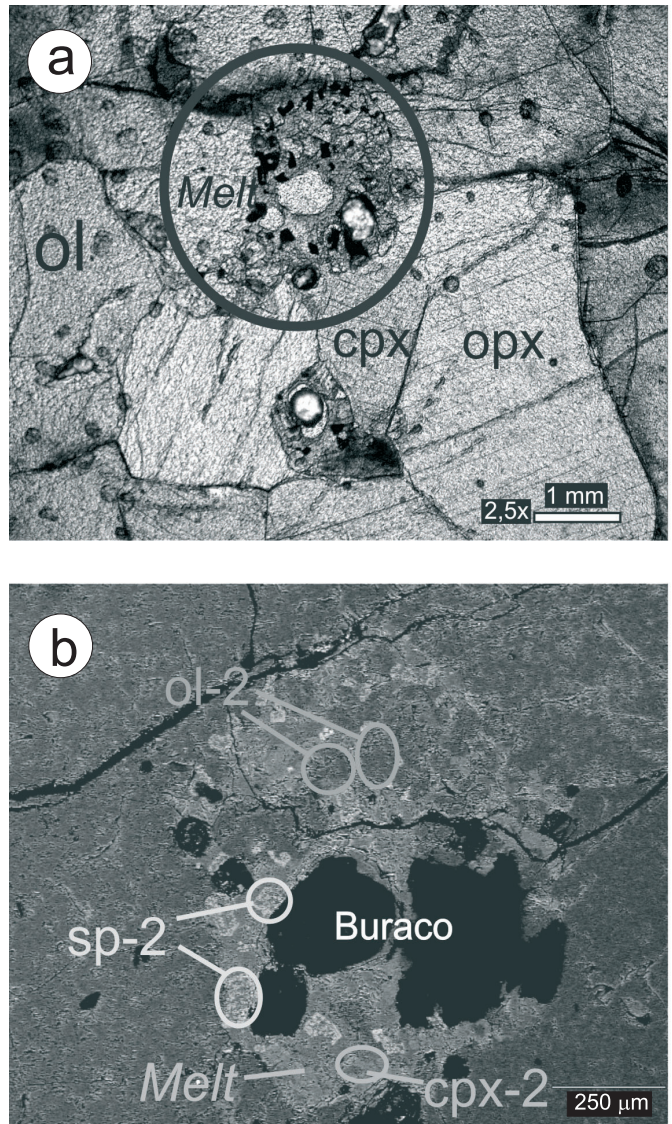

Comparando-se estes dados com xenólitos de outras localidades, verifica-se que estes resultados (Figura 4) apontam, de modo geral, para condições de pressão menores no Cerro de los Chenques que no Cerro Del Mojon e Estancia Alvarez, situados ao norte do Cerro estudado, que apontam valores entre 14 e 18 kbar e entre 11 e 18 kbar, respectivamente (Mallmann, 2004). As condições de temperatura são similares aos xenólitos do Cerro Del Mojon e levemente maiores que nos xenólitos da Estancia Alvarez (Mallmann, 2004). A Figura 4 mostra, ainda, as condições de pressão e temperatura de xenólitos de Praguaniyeu, ao norte, e do Lote 17, Cerro del Fraile e Pali-Aike, ao sul. As localidades Pali-Aike e Praguaniyeu foram submetidas às condições de pressão mais intensas, e isto é marcado petrograficamente pelo aparecimento de granada na paragênese mineralógica (Stern et al., 1999; Ntaflos, Bjerg, Labudía, 2002), como está indicado na Figura 4. Estas condições mais elevadas de pressão parecem não ter influência direta da placa subductada, contudo sugerem uma estabilidade mais próxima da geoterma oceânica do que da continental.
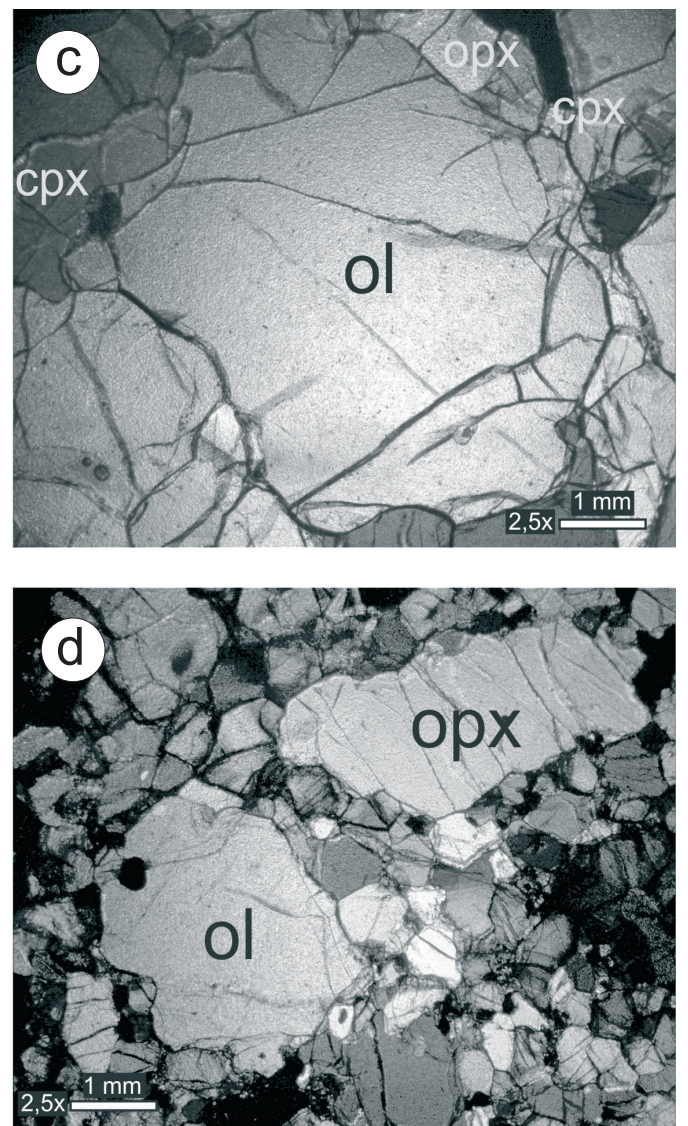

Figura 2. Fotomicrografias dos xenólitos do Cerro de los Chenques. a. Detalhe de um melt pocket. b. Detalhe de MEV (EDS) do melt pocket. c. Textura protogranular. d. Textura porfiroclástica a equigranular. 


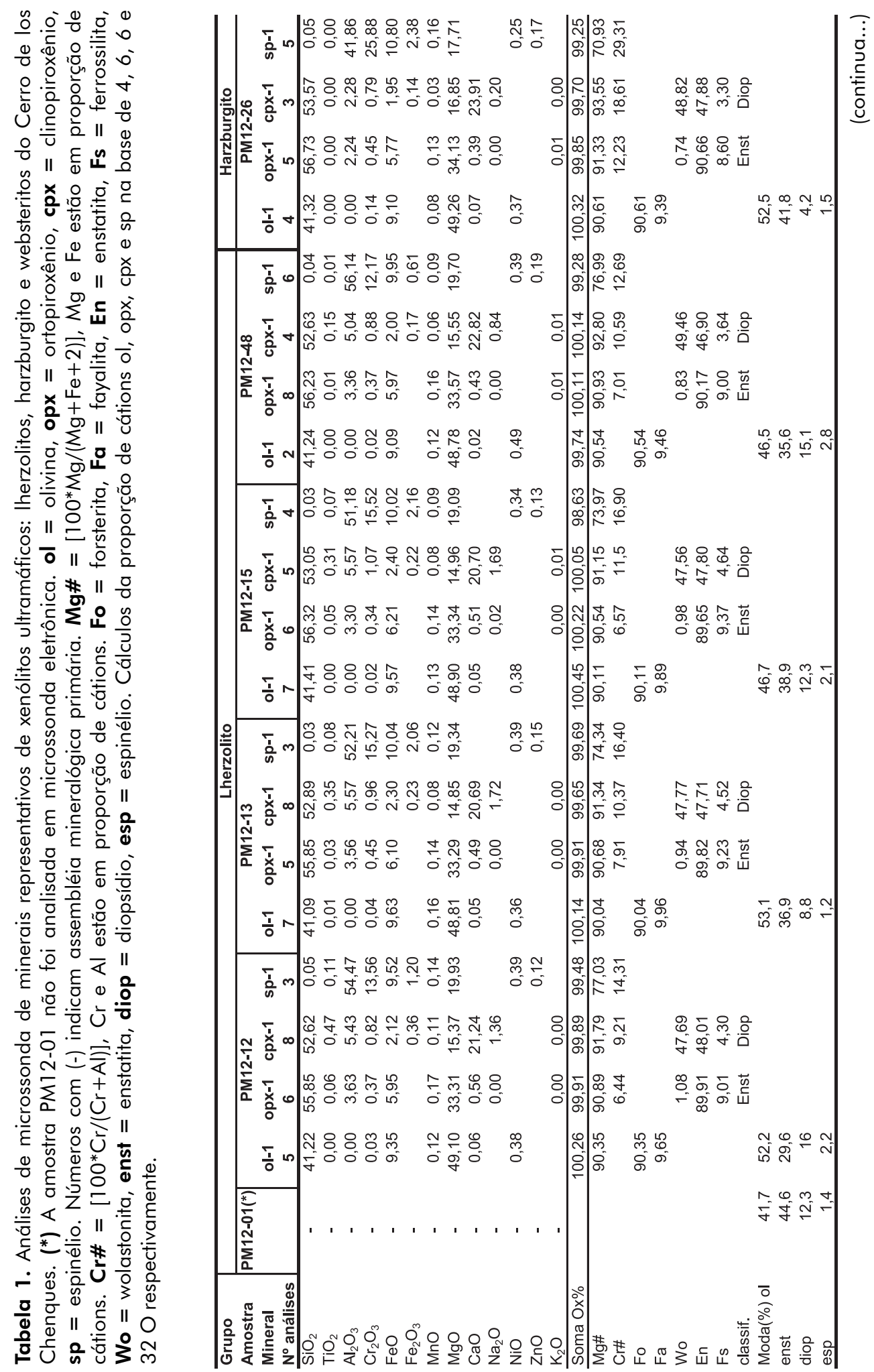



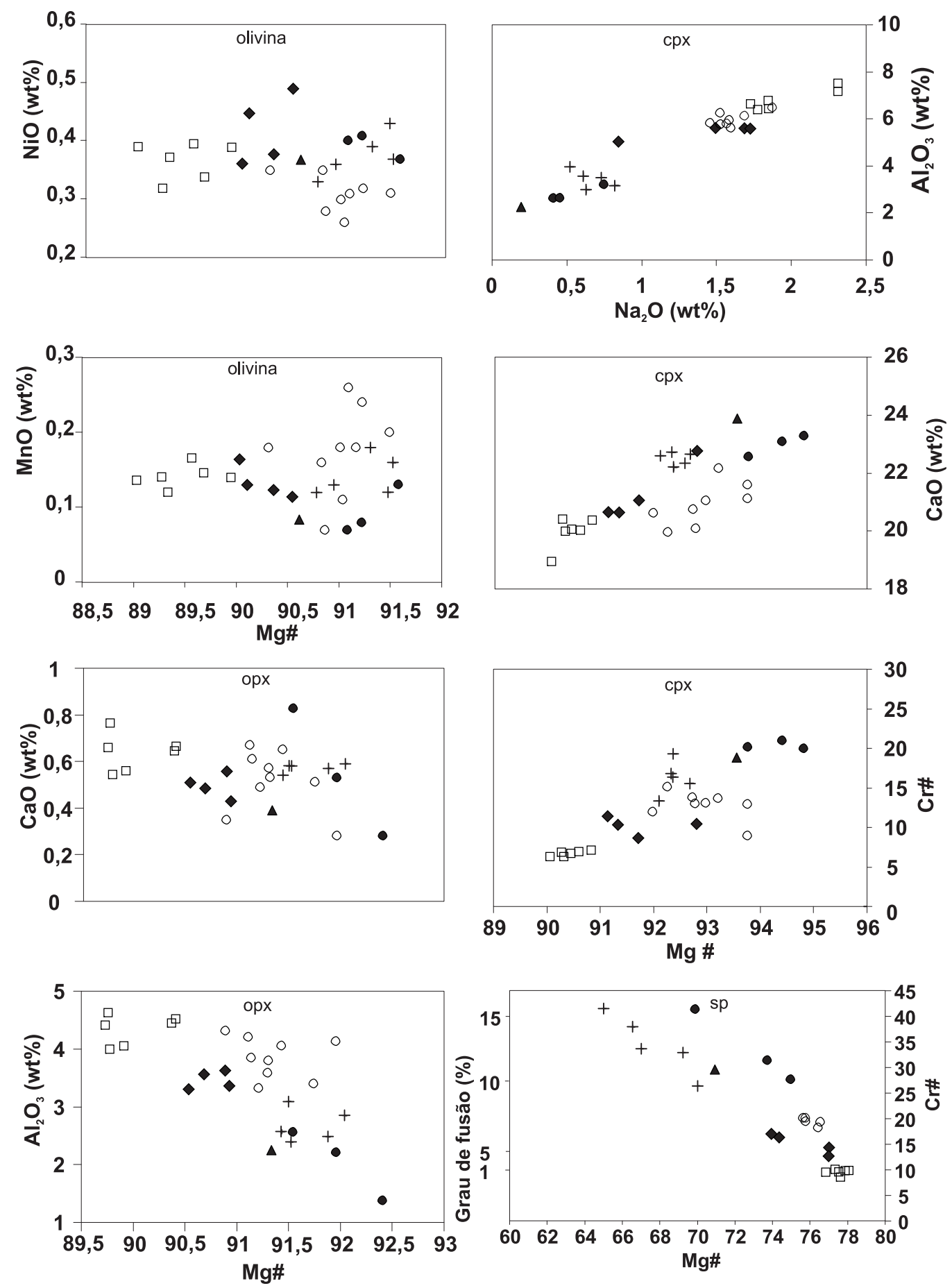

Cerro de los Chenques: $\quad$ Lherzolito

$\Delta \quad$ Harzburgito $\quad \square \quad$ Websterito

+ Cerro del Mojon • Estancia Alvarez $\circ \quad$ Cerro Redondo

Figura 3. Diagramas de variação composicional para elementos maiores dos minerais constituintes dos xenólitos ultramáficos. Relação do Cr\# de espinélio com grau de fusão (Hellebrand et al., 2001). 


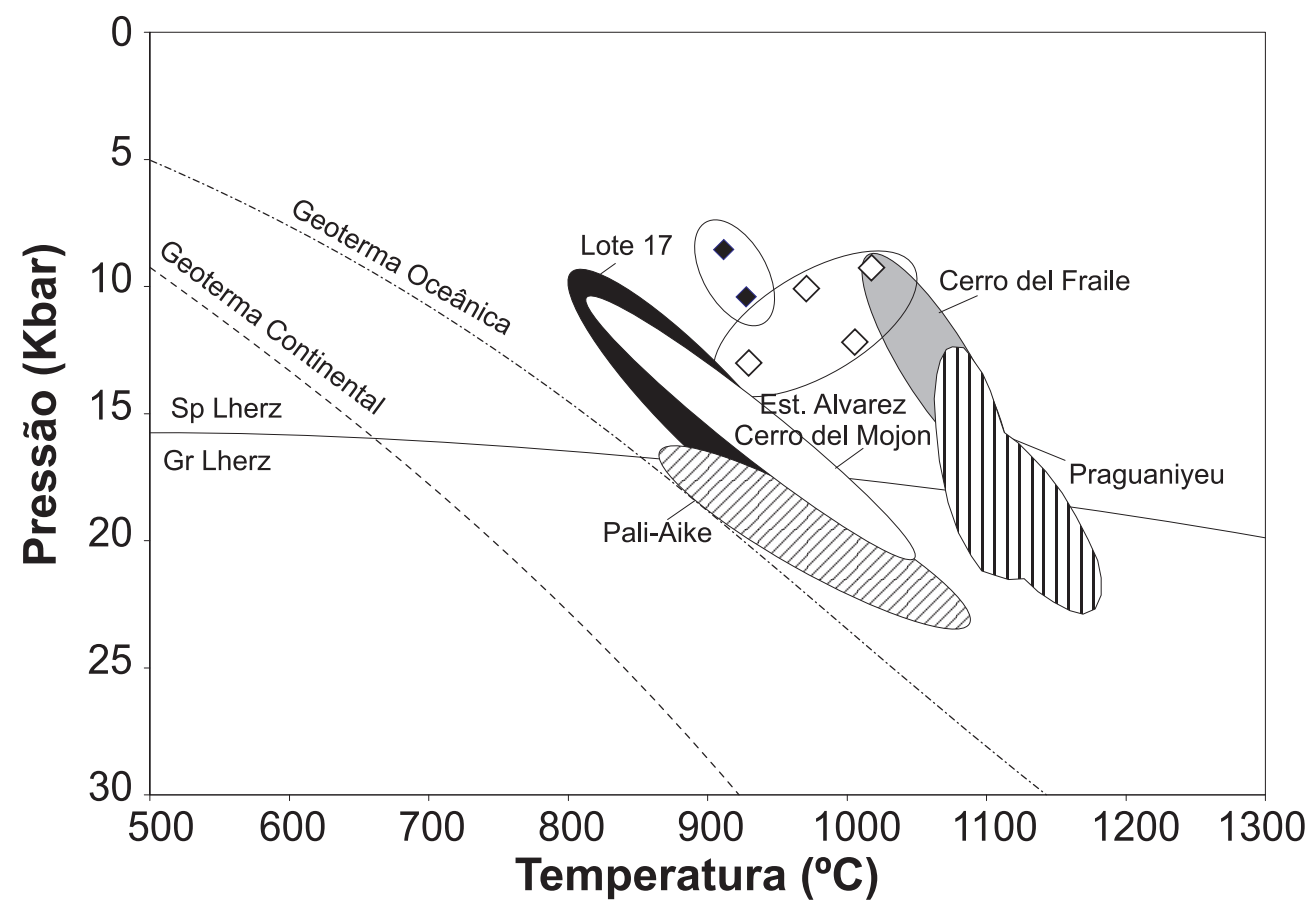

\section{Cerro de los Chenques $-\diamond$ Lherzolito $\diamond$ Websterito}

Praguaniyeu

Co. del Fraile

Lote 17

¿/ Pali-Aike

Est. Alvarez / Co. del Mojon

Figura 4. Estimativas de pressão e temperatura de equilíbrio da paragênese primária dos xenólitos estudados. Dados para comparação de Stern et al. (1999) (Pali-Aike), Gorring e Kay (2000) (Lote 17), Ntaflos et al. (2002) (Praguaniyeu), Kilian et al. (2002) (Cerro del Fraile) e Mallmann (2004) Cerro del Mojon e Estancia Alvarez). Estão indicadas também as geotermas continental e oceânica.

\section{GEOQUÍMICA DE ROCHA TOTAL}

As análises químicas para elementos maiores em rocha total dos xenólitos do Cerro de los Chenques estão expressas na Tabela 2. Estes dados apontam para o baixo grau de alteração das amostras analisadas, uma vez que os valores de perda ao fogo não foram detectados (ND). Apresentam, ainda, $\mathrm{Mg} \#\left[100 \mathrm{xMg} /\left(\mathrm{Mg}+\mathrm{Fe}_{\text {total }}\right)\right.$, em proporção molecular] variando de 88,1 a 90,3 , que são valores indicativos de amostras originadas no manto, como afirma McDonough (1990), que sugere Mg\# > 85 para xenólitos do manto.

A Figura 5 apresenta o comportamento químico de alguns óxidos de elementos maiores e menores do Cerro de los Chenques para rocha total em relação ao Mg\#, e compa- ra com dados de amostras de lherzolitos do Cerro Redondo (Schilling et al., 2005), ao sul, e de harzburgitos do Cerro Del Mojon e Estancia Alvarez (Mallmann, 2004; Conceição et al., 2005), ao norte e também com dados de Rivalenti et al. (2004) para duas amostras de lherzolitos e uma de harzburgito do próprio Cerro de los Chenques. Como está exemplificado na Figura 5, percebe-se que nestes locais o Mg\# dos xenólitos varia de 90 a 91 assim como para as amostras de Rivalenti et al. (2004), sendo maiores que o Mg\# dos xenólitos do Cerro de los Chenques. Isto é indicativo de que o Cerro de los Chenques, para as amostras estudadas, representa o manto litosférico menos depletado. Eventos posteriores, como metassomatismo, podem ser observados, conforme verificado a partir dos elementos traço (Figura 6) e mesmo pela correlação positiva 


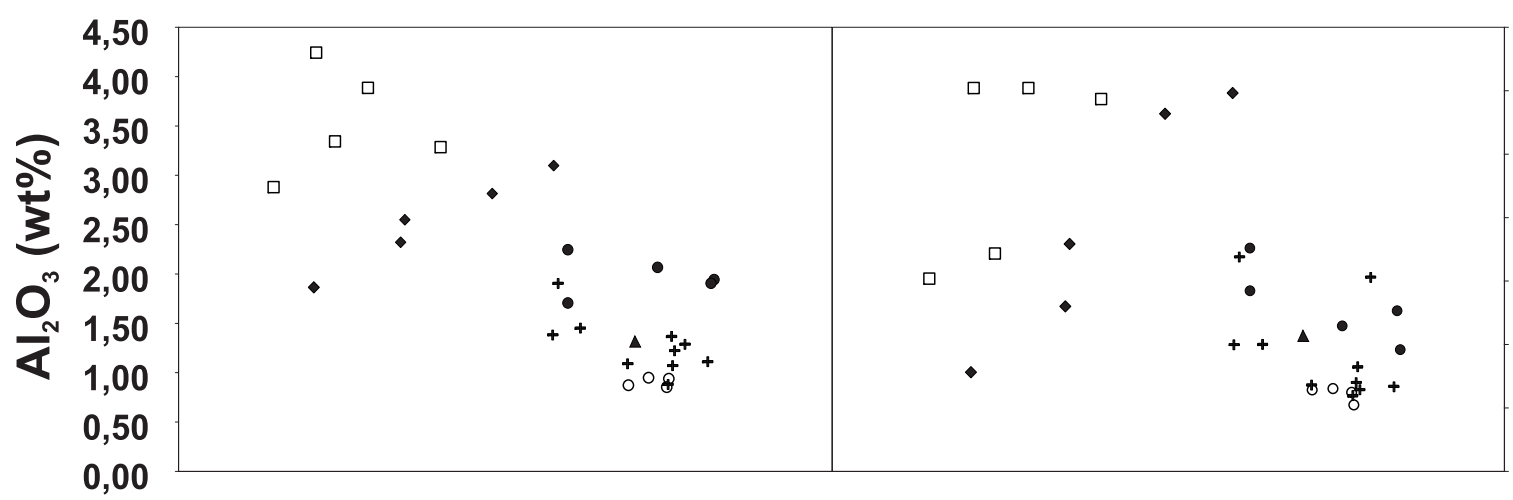

3,50

3,00

2,50

2,00

1,50

1,00

0,50

0,00

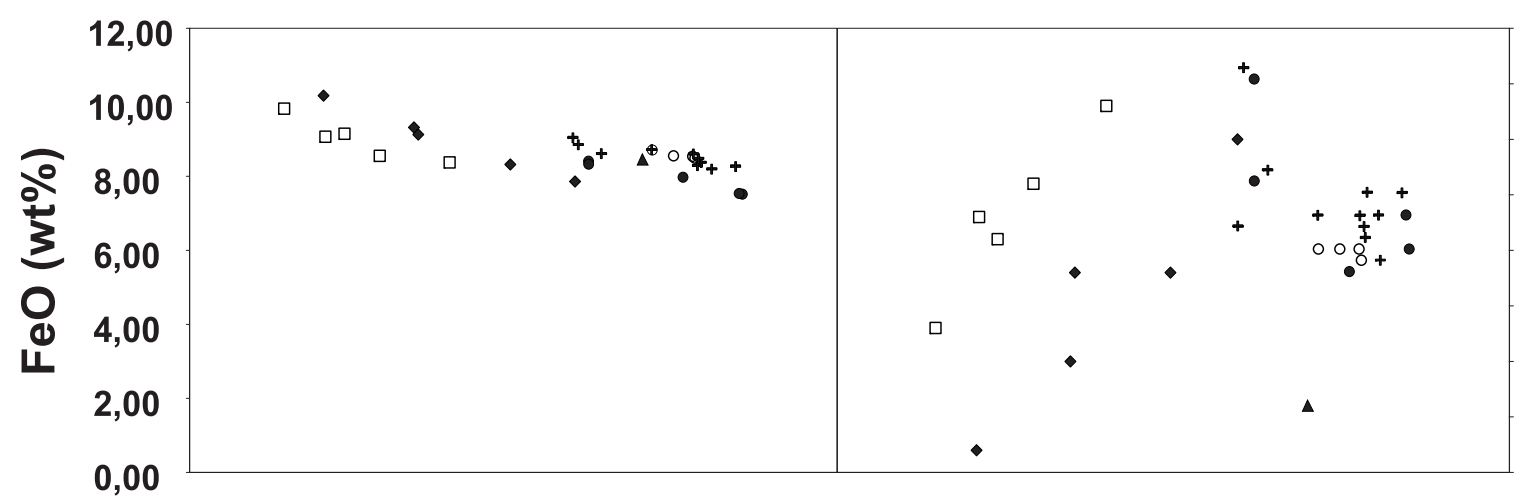

0,40

0,35

0,30

0,25

0,20

0,15

0,10

0,05

0,00

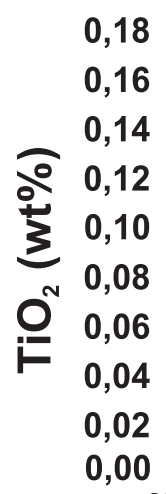

0,18

0,40

0,35
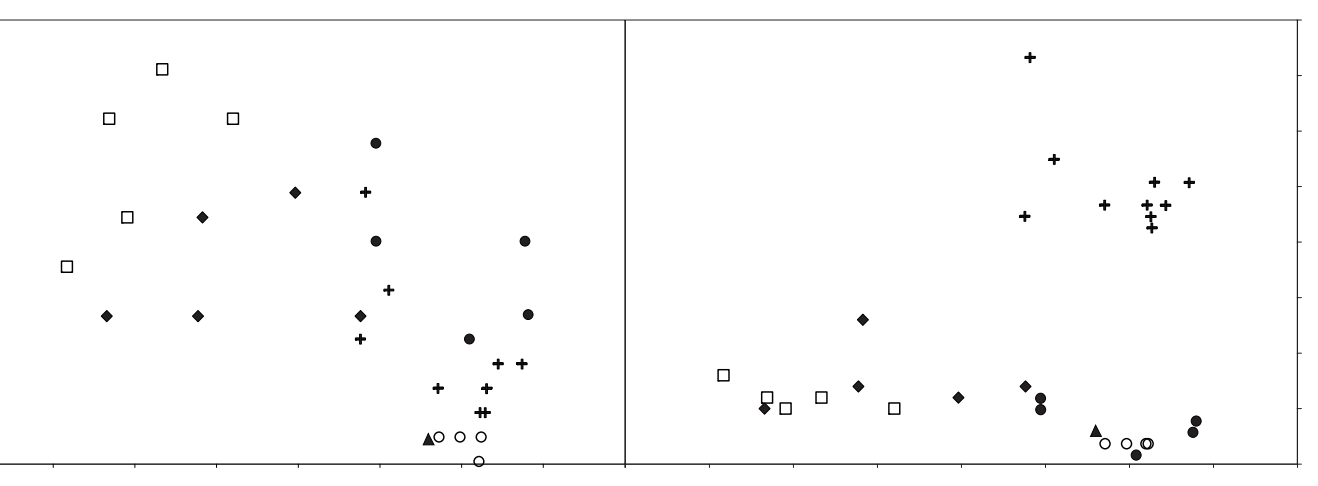

0,30

0,25

0,20

0,15

0,10

$\begin{array}{lllllllllllllllll}87,5 & 88 & 88,5 & 89 & 89,5 & 90 & 90,5 & 91 & 87,5 & 88 & 88,5 & 89 & 89,5 & 90 & 90,5 & 91 & 91,5\end{array}$

0,05 0,00

\section{Mg\#}

Mg\#

$$
\text { Cerro de los Chenques } \bullet \text { Lherzolito } \square \text { Websterito } \Delta \text { Harzburgito }
$$

\section{$+\quad$ Cerro del Mojon $\quad$ Estancia Alvarez $\quad \bigcirc \quad$ Cerro Redondo}

Figura 5. Diagrama de variação da composição de óxidos de elementos maiores e menores em rocha total, plotados contra o Mg\#. 
Tabela 2. Composição química dos elementos maiores e menores em \% de óxidos, perda ao fogo (ND = não detectado), $\mathrm{Mg} \#$ e razões $\mathrm{CaO}, \mathrm{Na}_{2} \mathrm{O}$ e $\mathrm{K}_{2} \mathrm{O}$ versus $\mathrm{Al}_{2} \mathrm{O}_{3}$ para os xenólitos ultramáficos do Cerro de los Chenques. Composição química dos elementos traço (ppm e $\left.\left(^{*}\right)-p p b\right)$ dos xenólitos ultramáficos do Cerro de los Chenques.

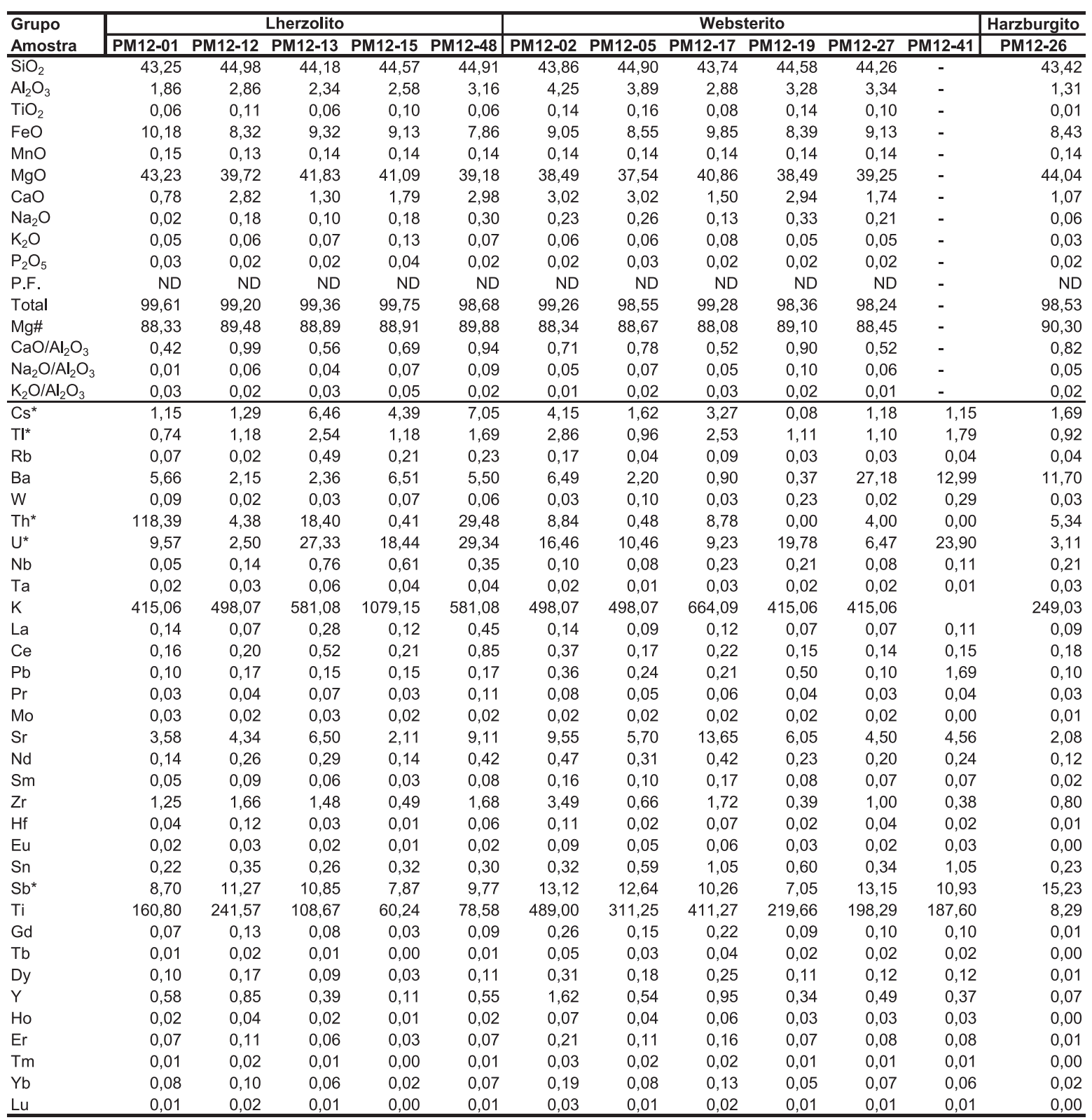


entre $\mathrm{Mg \#} \mathrm{e} \mathrm{Na}_{2} \mathrm{O}, \mathrm{CaO}, \mathrm{TiO}_{2}$ e $\mathrm{Al}_{2} \mathrm{O}_{3}$. Os xenólitos estudados apresentam padrão levemente enriquecido nos óxidos analisados do que nas demais localidades, sendo levemente mais depletado apenas no $\mathrm{Na}_{2} \mathrm{O}$ para alguns lherzolitos e harzburgitos. Os óxidos dos xenólitos do Cerro de los Chenques, analisados na Figura 5, de modo geral são levemente empobrecidos em relação ao manto primitivo proposto por Palme e Nickel (1985).

Os dados de elementos traço das amostras de xenólitos ultramáficos do Cerro de los Chenques estão relatados na Tabela 2. Estes dados apresentam um trend composicional levemente depletado em relação ao manto primitivo, como está demonstrado na Figura 6a. O trend, que pode ser definido como principal, apresenta empobrecimento nos HFSE (Th, Zr, Hf e Eu) e enriquecimento nos HFSE (U, Ta e $\mathrm{Pb}$ ) e W, Sn e Sb. Porém, nota-se que os LILE (Rb e Ba) nos websteritos possuem anomalia negativa, enquanto que os lherzolitos, o harzburgito e o websterito PM12-27 apresentam anomalias positivas no LILE (Ba). Na Figura 6a, pode-se observar, ainda, que as amostras PM12-13 (lherzolito) e PM12-41 (websterito) apresentam uma pequena variação em relação a esse trend composicional principal, com enriquecimento em $\mathrm{Rb}$ e $\mathrm{Ba}$, respectivamente. As amostras PM12-26 (harzburgito) e PM12-15 (lherzolito) diferem deste trend por ter um padrão mais empobrecido nos HFSE, que estão dispostos do Ti ao Lu. Observa-se também uma anomalia negativa no Y, que aumenta da amostra mais enriquecida para a mais empobrecida. Esta anomalia não existe no harzburgito. A amostra PM12-26 registra ainda um empobrecimento em Eu e Ti. As amostras de websterito PM12-05 e de lherzolito PM12-15 diferem do trend principal por um maior empobrecimento em Th. A amostra de websterito PM12-19 é a única que registra depleção em Cs, diferentemente do padrão principal, e o lherzolito PM12-12 tem empobrecimento em Zr. As anomalias positivas em W, Pb, Sn e Sb são superiores aos valores do manto primitivo.

Os dados de elementos traço do Cerro de los Chenques, quando comparados com dados dos xenólitos ultramáficos do Cerro Redondo (Schilling et al., 2005) e do Cerro del Mojon e da Estancia Alvarez (Mallmann, 2004; Conceição et al., 2005), apresentam, de modo geral, algumas similaridades nas concentrações. Porém, é possível observar que no Cerro Redondo ocorrem as maiores concentrações de Th, U, Nb, La, Sr, Nd, Sm, Zr e Hf, e altas concentrações de Gd, Y, Ho, Er, Yb e Lu. No Cerro Del Mojon e na Estancia Alvarez, observam-se concentrações maiores nos elementos traço crustais (Cs, Tl, Rb e Ba) em relação ao Cerro de los Chenques, sendo o padrão de distribuição das concentrações nos xenólitos harzburgíticos de Estancia Alvarez mais similar ao do Cerro de los Chenques, principalmente na amostra de lherzolito (PM12-15) e de harzburgito (PM12-26). No
Cerro de los Chenques, observam-se algumas diferenças marcantes, em relação às demais localidades, como o grande empobrecimento em Th e Ti e o grande enriquecimento em W e Sn.

Analisando-se o comportamento geoquímico dos ETR dos xenólitos do Cerro de los Chenques (Figura 6b), fica possível determinar 3 trends composicionais, todos depletados em relação ao manto primitivo. O trend principal é representado pelas amostras de lherzolitos PM12-01 e PM12-12 $\left(\mathrm{La}_{\mathrm{N}} / \mathrm{Lu}_{\mathrm{N}}: 0,5-1,1 ; \mathrm{Ce}_{\mathrm{N}} / \mathrm{Sm}_{\mathrm{N}}\right.$ : $, 6-0,8$ e $\mathrm{Dy}_{\mathrm{N}} / \mathrm{Lu}_{\mathrm{N}}$ : 0,8 - 1,1) e de websteritos PM12-02, PM12-05, PM12-17, PM12-19, PM12-27 e PM12-41 ( $\mathrm{La}_{\mathrm{N}} / \mathrm{Lu}_{\mathrm{N}}: 0,5$ - 1,3; $\mathrm{Ce}_{\mathrm{N}} / \mathrm{Sm}_{\mathrm{N}}$ : 0,3 - 0,6 e $\mathrm{Dy}_{\mathrm{N}} / \mathrm{Lu}_{\mathrm{N}}: 1$ - 1,4), caracterizado por um padrão empobrecido em ETR leves em comparação com os ETR pesados, estes últimos com um padrão horizontalizado. A amostra PM12-02 é a mais enriquecida, enquanto que a PM12-15 é a mais empobrecida. Os outros 2 trends composicionais são muito similares, como está representado na Figura 6b, apresentando enriquecimento em ETR leves em relação aos pesados. Porém, o trend representado pelas amostras de lherzolito PM12-13 e PM12-48 (La: 0,41 - 0,65x; Sm: 0,15 - 0,19x e Lu: 0,13 - 0,15x Manto Primitivo) difere por ser mais enriquecido em ETR que o trend representado pelas amostras PM12-15 (lherzolito) e PM1226 (harzburgito) (La: 0,13 - 0,17x; Sm: 0,05 - 0,06 e Lu: 0,04 0,05x Manto Primitivo). Este último trend representa as amostras mais depletadas, coincidindo com os dados dos elementos traço. Nos websteritos ocorre anomalia negativa de Ce, inexistente na amostra PM12-02.

O trend definido como principal para os ETR do Cerro de los Chenques de modo geral tem uma diferença marcante em relação às composições de ETR de xenólitos harzburgíticos do Cerro del Mojon, Estancia Alvarez e lherzolíticos do Cerro Redondo, possuindo padrão empobrecido em ETR leves e enriquecido em ETR pesados, sugerindo que apenas as amostras do Cerro de los Chenques mantiveram os registros dos processos de extração de líquidos por fusão. Nas amostras PM12-13 e PM12-48, o padrão dos ETR assume um comportamento semelhante aos trends dos xenólitos do Cerro del Mojon (Mallmann, 2004; Conceição et al., 2005) e do Cerro Redondo (Schilling et al., 2005), onde se observa um enriquecimento de ETR leves em relação aos pesados, evidenciando o processo metassomático. Apesar disso, no Cerro Del Mojon e no Cerro Redondo, as concentrações dos ETR leves são mais elevadas, ocorrendo concentrações superiores às concentrações do manto primitivo. Os xenólitos de Estancia Alvarez (Mallmann, 2004; Conceição et al., 2005) apresentam um trend similar aos das amostras PM12-15 e PM12-26, as mais empobrecidas, com ETR leves enriquecidos em relação aos ETR pesados que apresentam concentrações muito baixas. 
(2)

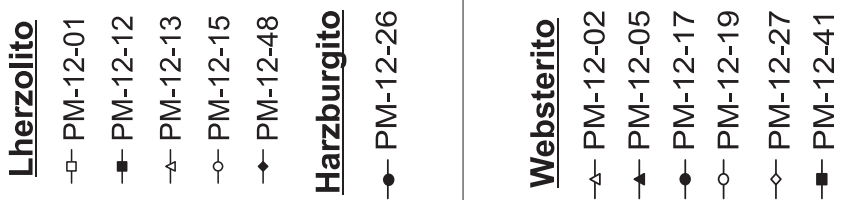

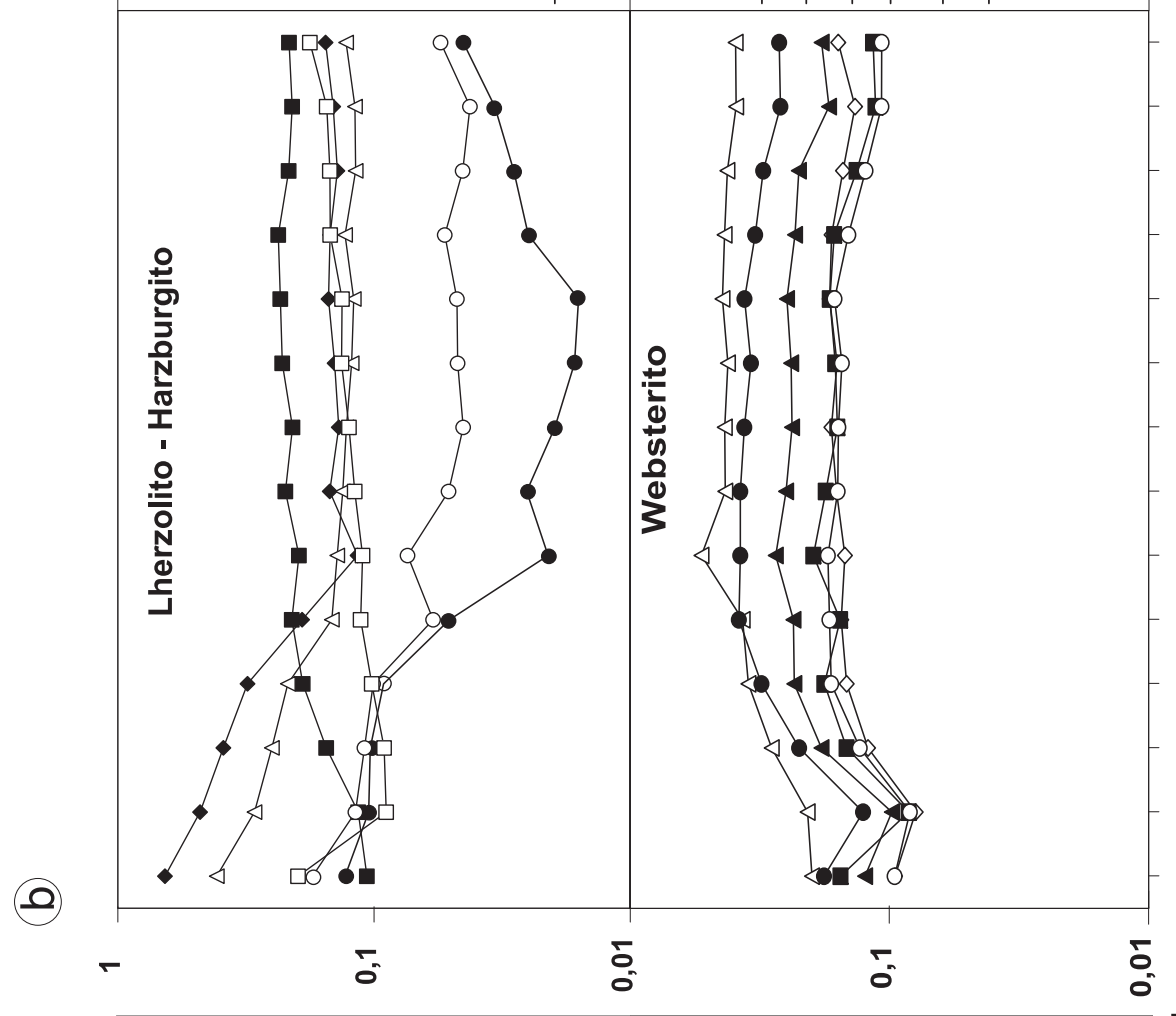

(ช)

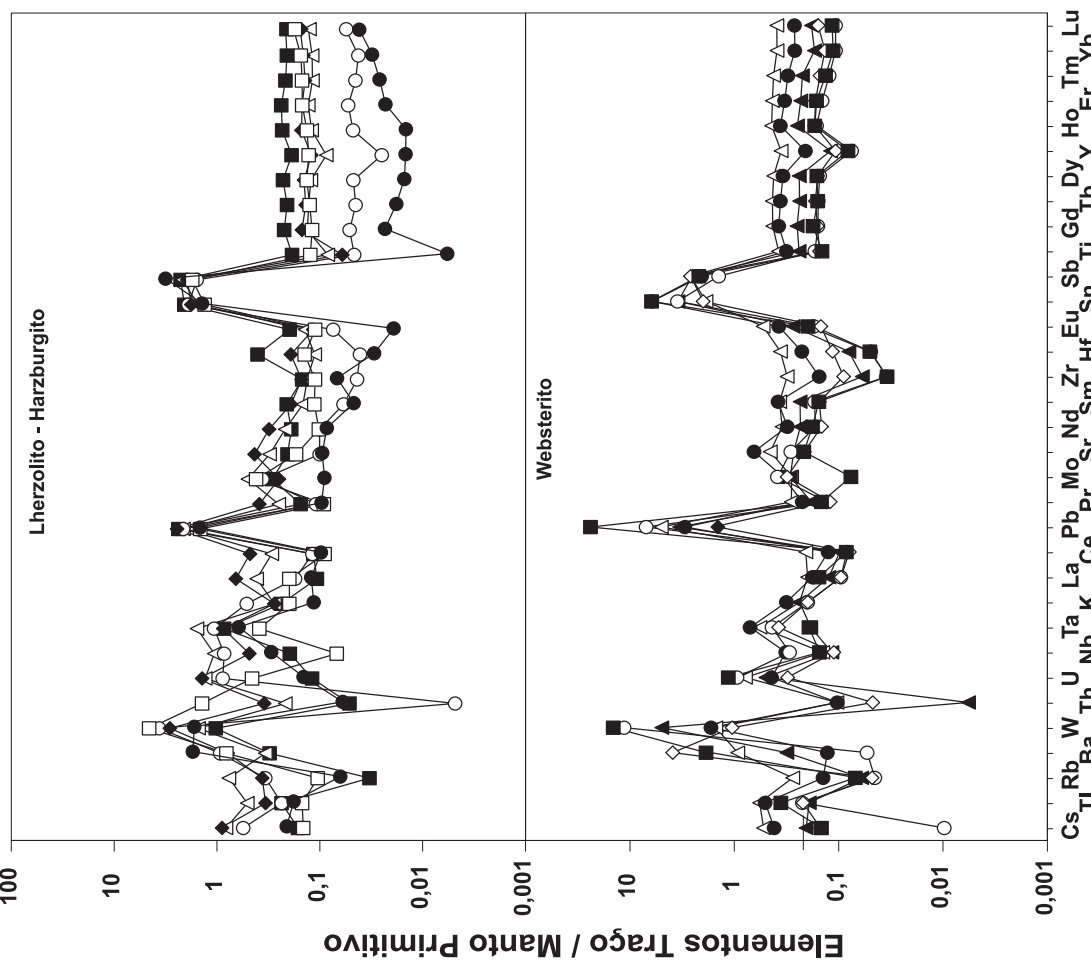




\section{DISCUSSÕES}

Os dados químicos de rocha total dos xenólitos estudados do Cerro de los Chenques têm evidências de processos de fusão parcial, que são caracterizados pelos menores teores dos óxidos de $\mathrm{Al}_{2} \mathrm{O}_{3}$, $\mathrm{CaO}$ e $\mathrm{TiO}_{2}$ em relação ao manto primitivo. Os valores dos dados obtidos indicam, no entanto, um grau de fusão menor do que nos xenólitos ultramáficos do Cerro Del Mojon, de Estancia Alvarez (Mallmann, 2004; Conceição et al., 2005), do Cerro Redondo (Schilling et al., 2005) e mesmo do Cerro de los Chenques (Rivalenti et al., 2004), pois nas amostras do Cerro de los Chenques estudadas há uma maior concentração principalmente no $\mathrm{Al}_{2} \mathrm{O}_{3} \mathrm{e}$ $\mathrm{CaO}$. Os elementos traço e os ETR são depletados em relação ao manto primitivo, corroborando com as evidências de fusão parcial. Além disso, pode-se afirmar que as amostras que possuem empobrecimento em ETR leves em relação aos pesados, como se observa pelas razões $\mathrm{La}_{\mathrm{N}} / \mathrm{Lu}_{\mathrm{N}}, \mathrm{Ce}_{\mathrm{N}} /$ $\mathrm{Sm}_{\mathrm{N}}$ e $\mathrm{Dy}_{\mathrm{N}} / \mathrm{Lu}_{\mathrm{N}}$, já citadas, caracterizam o processo de fusão parcial a que o manto superior foi submetido.

Os processos metassomáticos, posteriores à fusão parcial, são caracterizados pelo enriquecimento em ETR leves em relação aos pesados e petrograficamente podem estar associados à ocorrência da paragênese secundária (ol, cpx, sp) e melt pockets. As evidências químicas de metassomatismo estão presentes nas amostras PM12-48, PM12-13, PM12-15 e PM12-26, sendo as duas últimas as mais depletadas. Nestas amostras, observa-se um padrão de ETR em “U” similar ao já observado por Mallmann (2004) e por Schilling et al. (2005), indicador de metassomatismo críptico (McDonough, 1990) ou ainda de processos de cromatografia mantélica (Navon e Stopler, 1987). Nos elementos traço das amostras PM12-15 e PM12-26 (Figura 6a), nota-se um progressivo enriquecimento dos elementos mais compatíveis para os mais incompatíveis.

Rivalenti et al. (2004) afirmam que os componentes derivados da placa subductada induzem o enriquecimento em ETR leves e nos LILE, além do empobrecimento em Nb no manto metassomatizado, porém no Cerro de los Chenques não é possível afirmar sobre a influência da placa subductada, uma vez que ocorre pouco enriquecimento em LILE e não há anomalias negativas do $\mathrm{Nb}$.

Os lherzolitos do Cerro de los Chenques são mais depletados em todos os elementos traço analisados do que nos lherzolitos do Cerro del Mojon. Isto pode ser indicativo de um grau de fusão parcial mais elevado nos lherzolitos do Cerro de los Chenques. Entretanto, esta maior concentração nos traços dos lherzolitos do Cerro Del Mojon pode também indicar um maior metassomatismo em relação aos lherzolitos do Cerro de los Chenques, ou fontes originalmente distintas ou diferenciadas quanto aos teores de elementos traço.
Os valores mais elevados para o Cr\# no sp-1, como afirmam Hellebrand et al. (2001), principalmente na amostra PM12-26 (Figura 3), assim como na amostra PM12-15, bem como um padrão mais empobrecido em ETR com relação ao manto primitivo, sugerem que estas amostras sejam o resultado de um processo de fusão intenso e que correspondem ao resíduo dessa fusão. Entretanto, a tendência de re-enriquecimento em ETR leves em relação aos pesados indica que elas também sofreram o processo metassomático que todas as demais amostras, que mostram algum enriquecimento em ETR leves em relação aos pesados, devem ter passado. Esta elevada quantidade de Cr no sp-1 da amostra PM12-26 sugere ainda que a temperatura a que ela foi submetida foi maior que nas demais, corroborando a sugestão de que o harzburgito tem a maior característica refratária observada nesse cerro. Contudo, as estimativas de temperatura de equilíbrio desta amostra não fornecem dados coerentes, registrando valores de $787^{\circ} \mathrm{C}$, menores que nas demais amostras analisadas.

O Cr\# no sp-1 (valor máximo = 29,31 - PM12-26) indica ainda que os xenólitos estudados não sofreram forte tectonismo, como postula Bjerg et al. (2005), que aponta Cr\# no sp-1 > 40 para xenólitos altamente tectonizados e recristalizados. Entretanto, texturalmente há indícios de recristalização acentuada, devido à ocorrência de textura equigranular (Mercier e Nicolas, 1975), nas amostras PM12-01, PM12-02, PM12-26 e PM12-27.

Assim, os xenólitos mantélicos do Cerro de los Chenques permitem tecer considerações quanto à evolução do manto litosférico continental da região. Integrando os dados de campo, petrográficos de química mineral e de química de rocha, podem-se observar a presença de xenólitos com duas origens distintas, os peridotitos (lherzolitos e harzburgitos) e os piroxenitos (websteritos). Esses dois grupos podem ser individualizados quando são analisados os diagramas de geoquímica de rocha total, onde dois trends distintos ocorrem, como, por exemplo, nos diagramas Mg\# versus $\mathrm{TiO}_{2}, \mathrm{CaO}, \mathrm{Al}_{2} \mathrm{O}_{3}$ e $\mathrm{Na}_{2} \mathrm{O}$. Esse tipo de comportamento geoquímico não pode ser explicado a partir de um único evento, como exemplo, de fusão parcial ou cristalização fracionada, uma vez que os mesmos produziriam trends únicos (se fossem rochas geradas em um único evento), bem como com correlações negativas.

Os peridotitos, então, podem ser interpretados como vinculados a um processo de fusão parcial, conforme demonstrado pela concentração depletada em relação ao manto primitivo, bem como padrão flat dos elementos terras raras médios a pesados. Os websteritos apresentam Mg\# menor do que os peridotitos, e assim não podem ser considerados como o resíduo refratário de um evento de fusão parcial vinculado aos peridotitos. Por sua vez, a origem dos websteritos tem sido amplamente discutida na literatura, ou 
relacionados a processos de fusão, onde os mesmos seriam cumulatos formados a partir da extração de um líquido (Niu, 1997; Mukasa e Shervais, 1999; Herzberg, 2004), ou relacionados a processos metassomáticos, onde os websteritos representariam canais de focoused melt percolation e os peridotitos a rocha encaixante metassomatizada, a partir do mecanismo de reactive porous flow (Bedini et al., 1997; Vernieres et al., 1997; Rivalenti et al., 2004).

Quando os padrões de terras raras dos websteritos são analisados, observa-se a depleção desses elementos em relação ao manto depletado, bem como um padrão com $\mathrm{Sm}_{\mathrm{N}} / \mathrm{Yb}_{\mathrm{N}}>1$, o que é sugestivo de uma origem desses xenólitos a partir de um evento de fusão de um manto com granada, ou seja, causando a depleção em terras raras pesados. Assim, os peridotitos e os websteritos representam dois eventos distintos, provavelmente vinculados a duas fusões do manto, em tempos diferentes com composições distintas, um deles rico em granada. Cabe ressaltar que o enriquecimento nas concentrações de elementos terras raras leves, tanto nos peridotitos como nos websteritos pode ser vinculado à infiltração de um componente metassomático (basalto?), o que pode ser corroborado por feições petrográficas, como a presença de melt pockets, por vezes interpretados como resultantes por descompressão (Rivalenti et al., 2004), vinculada à ascensão dos xenólitos até a superfície, interagindo com líquidos silicáticos (basaltos alcalinos), bem como anomalias observadas em elementos traços incompatíveis, como por exemplo, Tl, Mo, U, Ta e Zr.

\section{CONCLUSÕES}

As rochas encaixantes da suíte de xenólitos ultramáficos do Cerro de los Chenques são rochas piroclásticas de composição basáltica. Os xenólitos ultramáficos do Cerro de los Chenques são representados por lherzolitos, harzburgitos e websteritos, com o espinélio como fase aluminosa presente. As texturas observadas, de acordo com Mercier e Nicolas (1975), são protogranular, porfiroclástica e equigranular, com predominância de textura transicional porfiroclásticaequigranular. A paragênese primária está em equilíbrio químico (Mg\# olivina < Mg\# enstatita < Mg\# diopsídio), porém ocorrem instabilidades com formação de uma paragênese secundária, composta por olivina, diopsídio e espinélio e vidro silicático.

Os dados de química de rocha total para elementos maiores mostram fracionamento nos óxidos, principalmente nos álcalis, em relação ao manto primitivo, assim como nos elementos traço. Esse empobrecimento é indicativo de processo de fusão parcial. As amostras que apresentam padrões de ETR enriquecidos em ETR pesados em relação aos leves também são indicativas de fusão parcial no manto. As amos- tras que apresentam padrão de ETR enriquecido em ETR leves em relação aos pesados são indicativas de processo de metassomatismo. O metassomatismo também é evidenciado, no Cerro de los Chenques, pela ocorrência de recristalizações contendo vidro silicático, além de olivina, espinélio e clinopiroxênio de segunda geração.

Integrando-se os dados de campo, petrográficos, de química mineral e de geoquímica, sugere-se que o manto litosférico abaixo da região do Cerro de los Chenques foi afetado por dois processos envolvidos em sua formação. Em um primeiro processo ocorre fusão do manto superior e geração de um manto depletado, registrado nos peridotitos e a fusão de um manto profundo, enriquecido em granada e a geração de websteritos; e um segundo processo, o metassomatismo críptico, com re-enriquecimento (líquidos silicáticos) desse manto depletado (peridotitos e websteritos), registrado nos xenólitos pelo aumento nos teores de ETR leves e melt pockets.

\section{AGRADECIMENTOS}

Agradecemos aos revisores anônimos deste artigo pelas importantes sugestões e observações para que as informações prestadas estejam claras e concisas. Ao Instituto de Geociências (UFRGS) pela disponibilização da infraestrutura, como Laboratório de Microscopia, o Centro de Microscopia Eletrônica e o Laboratório de Fluorescência de Raios X. Ao laboratório LMTG - Université Paul Sabatier, Toulouse, pela disponibilização da microssonda eletrônica. Por fim ao CNPq, pela bolsa de mestrado concedida e pelo apoio financeiro através do projeto 475990/2004-8.

\section{REFERÊNCIAS BIBLIOGRÁFICAS}

BENDINI, R. M.; BODINIER, J. L.; DAUTRIA, J. M. M.; MORTEN, L. Evolution o LILE-enriched smal melt fractions in the lithospheric mantle: a case study from the East Asian Rift. Earth and Planetary Science Letters, Amsterdam, v. 153, n. 1-2, p. 67-83, 1997.

BJERG, E. A.; NTAFLOS, T.; KURAT, G.; DOBOSI, G.; LABUDÍA, C. H. The upper mantle beneath Patagonia, Argentina, documented by xenoliths from alkali basalts. Journal of South American Earth Sciences, Oxford, v. 18, n. 2, p. 125-145, 2005.

BREY, G. P.; KÖHLER, T. Geothermobarometry in four-phase lherzolites II. New thermobarometers and practical assessment of existing thermobarometers. Journal of Petrology, Oxford, v. 31, n. 6, p. 1353-1378, 1990.

CANDIE, S. C.; LESLIE, R. B. Late Cenozoic tectonics of the 
southern Chile Trench. Journal of Geophysical Research, Washington, v. 19, n. B1, p. 495-520, 1986.

CONCEIÇÃO, R. V.; MALLMANN, G.; KOESTER, E.; SCHILLING M.; BERTOTTO, G W.; RODRIGUES-VARGAS, A. Andean subduction-related mantle xenoliths: isotopic evidence of Sr-Nd decoupling during metasomatism. Lithos, Oslo, v. 82, n. 3-4, p. 273-287, 2005.

GORRING, M. L.; KAY, S. M.; ZEITLER, P. K.; RAMOS, V. A.; RUBIOLO, D.; FERNANDEZ, M. I.; PANZA, J. L. Neogene Patagonian plateau lavas: continental magmas associated with ridge collision at the Chile Triple Junction. Tectonics, Washington, v. 16, n. 1, p. 1-17, 1997.

GORRING, M. L.; KAY, S. Carbonatite metassomatized peridotite xenoliths from the southern Patagonia: Implications for the litospheric processes and Neogene plateau magmatism. Contributions to Mineralogy and Petrology, Berlim, v. 140, n. 1, p. 55-72. 2000.

GORRING, M. L.; KAY, S. Mantle processes and sources of Neogene slab windows magmas from southern Patagonia, Argentina. Journal of Petrology, Oxford, v. 42, n. 6, p. 1067-1094, 2001.

HELLEBRAND, E.; SNOW, J. E.; DICK, H. J. B.; HOFFMANN, A. W. Coupled major and trace elements as indicators of the extent of melting in mid-ocean-ridge peridotites. Nature, London, v. 410, p. 677-681, 2001.

HERZBERG, G. Geodynamic information in peridotite petrology. Journal of Petrology, Oxford, v. 45, n. 12, p. 2507-2530, 2004.

KAY, S. M.; ARDOLINO, A. A.; FRANCHI, M.; RAMOS, V. A.; The Somuncura plateau: an Oligo-Miocene 'babyhotspot' in extra-Andean Patagonia (40.5o to 43.5o Latitude). Eos, Transaction of American Geophysical Union, Washington, v. 7, p. 337, 1992.

KÖHLER, T. P.; BREY, G. P. Calcium exchange between olivine and clinopyroxene calibrated as a geothermobarometer for natural peridotites from 2 to $60 \mathrm{~kb}$ with applications. Geochimica et Cosmochimica Acta, Washington, v. 54, n. 9-10, p. 2375-2388, 1990.

MALLMANN, G. Processos e componentes mantélicos no norte da Patagônia (Argentina) e relações com a subducção Andina: evidências petrográficas, geoquímicas e isotópicas em xenólitos ultramáficos mantélicos. 2004. 103 f. Dissertação (Mestrado) - Instituto de Geociências, Universidade Federal do Rio Grande do Sul, Porto Alegre, 2004.

MCDONOUGH, W. F. Constraints on the composition of the continental lithospheric mantle. Earth and Planetary Science Letters, Amsterdam, v. 101, n. 1, p. 1-18, 1990.

MCDONOUGH, W. F.; FREY, F. A. REE in the upper mantle rocks. In: CHELSEA, Lipin B.; MCKAY, B.(Ed.). Geochemistry and mineralogy of Rare Earth Elements. Washington: Mineralogy Society of America, 1989. p. 99-145.

MERCIER, J. C. C.; NICOLAS, A. Textures and fabrics of upper mantle peridotites as illustrated by xenoliths from basalts. Journal of Petrology, Oxford, v. 16, n. 2, p. 454-487, 1975.

MUKASA, S. B.; SHERVAIS, J. W. Growth of subcontinental lithosphere: evidence from repeated dike injections in the Balmuccia lherzolite massif, Italian Alps. Lithos, Oslo, v. 48, n. 1-4, p. 287-316, 1999.

NTAFLOS, T. H.; BJERG, E. A.; LABUDÍA, C. H. High temperature, low pressure garnet-peridotites from Praguaniyeu: evidence for plume activity in northern Patagonia In: CONGRESSO GEOLOGICOARGENTINO, 15., 2002, Calafate. Actas...Calfate, 2002. p. 53-55.

NAVON, O.; STOPLER, E. Geochemical consequences of melt percolation: the upper mantle as a chromatographic column. Journal of Geology, Washington, v. 95, n. 2, p. 285-307, 1987.

NIU, Y. Mantle melting and melt extraction processes beneath ocean ridges: evidence from abyssal peridotites. Journal of Petrology, Oxford, v. 38, n. 8, p. 1047-1074, 1997.

PALME, H.; NICKEL, K. G. Ca/Al ratio and composition of the Earth's upper mantle. Geochemica et Cosmochimica Acta, Washington, v. 49, n. 10, p. 2123-2132, 1985.

PLOSZKIEWICZ, V. Descripción geológica de la Hoja 47c, Apeleg. Buenos Aires: Servicio Geológico Nacional, 1987. 101p. (Boletín, 204).

RAMOS, V. A.; KAY, S. M. Southern Patagonian plateau basalts and deformation: backarc testimony of ridge collisions. Tectonophysics, Amsterdam, v. 205, n. 1-3, p. 261282, 1992.

RAMOS, V. A.; NIEMEYER, H.; SKARMETA, J.; MUNÑOZ, J. Magmatic evolution of the austral Patagonian Andes. Earth Science Reviews, Amsterdam, v. 18, n. 3-4, p. 411-443, 1982. 
RIVALENTI, G.; MAZZUCCHELLI, M.; LAURORA, A.; CIUFFI, S. I.A.; ZANETTI,A.; VANNUCCI, R.; CINGOLANI, C. A. The backarc mantle lithosphere in Patagonia, South America. Journal of South American Earth Sciences, Oxford, v. 17, n. 2, p. 121-152, 2004.

SCHILLING, M.; CONCEIÇÃO, R. V.; MALLMANN, G.; KOESTER, E.; KAWASHITA, K.; HERVÉ, F.; MORATA, D.; MOTOKI, A. Spinel mantle xenoliths from Cerro Redondo, Argentine Patagonia: Petrographic, geochemical and isotopic evidence of interaction between xenoliths and hostbasalts. Lithos, Oslo, v. 82, n. 3-4, p. 485-502, 2005.

STERN, C. R.; KILIAN, R.; OLKER, B.; HAURI, E. H.; KYSER, T. K. Evidence from mantle xenoliths for relatively thin-100km below the Phanerozoic crust of southernmost South America. Lithos, Oslo, v. 48, n. 1-4, p. 217-235, 1999.

VERNIÉRES, J.; GODARD, M.; BODINIER, J. L. A plate model for the simulation of trace element fractionation during partial melting and magma transport in the Earth's upper mantel. Journal of Geophysical Research, Washington, v. 102, n. B11, p. 24-711, 1997. 